\title{
Induced Second Trimester Abortion and Associated Factors in Amhara Region Referral Hospitals
}

\author{
Amlaku Mulat, ${ }^{1}$ Hinsermu Bayu, ${ }^{1}$ Habtamu Mellie, ${ }^{2}$ and Amare Alemu ${ }^{3}$ \\ ${ }^{1}$ Department of Midwifery, College of Health Sciences, Mekelle University, P.O. Box 1871, Mekelle, Ethiopia \\ ${ }^{2}$ Department of Public Health, College of Medicine and Health Sciences, Debre Markos University, Debre Markos, Ethiopia \\ ${ }^{3}$ Department of Midwifery, College of Medicine and Health Sciences, Bahirdar University, Bahirdar, Ethiopia \\ Correspondence should be addressed to Amlaku Mulat; tsion2006a@gmail.com
}

Received 20 January 2015; Revised 9 March 2015; Accepted 16 March 2015

Academic Editor: Sohinee Bhattacharya

Copyright (C) 2015 Amlaku Mulat et al. This is an open access article distributed under the Creative Commons Attribution License, which permits unrestricted use, distribution, and reproduction in any medium, provided the original work is properly cited.

\begin{abstract}
Background. Although the vast majority of abortions are performed in the first trimester, still 10-15\% of terminations of pregnancies have taken place in the second trimester period globally. As compared to first trimester, second trimester abortions are disproportionately contribute for maternal morbidity and mortality especially in low-resource countries where access to safe second trimester abortion is limited. The main aim of this study was to assess the prevalence and associated factors of induced second trimester abortion in Amhara region referral hospitals, northwest Ethiopia. Methods. Institution based cross-sectional study was conducted in Amhara region referral hospitals among 416 women who sought abortion services. Participants were selected using systematic sampling technique. Data were collected using pretested structured questionnaire through interviewing. After the data were entered and analyzed; variables which have $P$ value $<0.2$ in bivariate analysis, not colinear, were entered into multiple logistic regressions to see the net effect with $95 \% \mathrm{CI}$ and $P$ value $<0.05$. Results. The prevalence of induced second trimester abortion was $19.2 \%$. Being rural $(\mathrm{AOR}=1.86[95 \% \mathrm{CI}=1.11-3.14])$, having irregular menstrual cycle $(\mathrm{AOR}=1.76[95 \% \mathrm{CI}=1.03-2.98])$, not recognizing their pregnancy at early time $(\mathrm{AOR}=2.05[95 \% \mathrm{CI}=1.21-3.48])$, and having logistics related problems $(\mathrm{AOR}=2.37[95 \%$ $\mathrm{CI}=1.02-5.53]$ ) were found to have statistically significant association with induced second trimester abortion. Conclusion. Induced second trimester abortion is high despite the availability of first trimester abortion services. Therefore, increase accessibility and availability of safe second trimester abortion services below referral level, counseling and logistical support are helpful to minimize late abortions.
\end{abstract}

\section{Introduction}

Second trimester abortion is termination of pregnancy in a period from 13 to 28 weeks of gestation, which again is subdivided into early period between 13 and 20 weeks and late period between 20 and 28 weeks [1]. Globally, over 42 million abortions are performed annually and $10-15 \%$ of the cases take place in second trimester period, over half of which are considered unsafe, and disproportionately contribute to maternal deaths [2]. In 2008, there were 29 abortions per 1,000 women aged 15-44 years in developing countries, compared with 24 per 1,000 in the developed world $[3,4]$.

As researches showed, the prevalence of induced second trimester abortion was as high as $25 \%-30 \%$ in India and South Africa [5], 8.6\% in England and Wales [6], 34\% in
Kenya [7], 10\% in Nigeria [8], and in 2008 there were 382,000 induced abortions performed in Ethiopia; about $42 \%$ of pregnancies were unintended and the rate of abortion was 101 per 1,000 women [9].

Abortion-related complications account for approximately $13 \%$ of maternal deaths worldwide, roughly estimated as 47000 deaths per year. Second trimester abortion carries a higher risk of morbidity and mortality as compared to first trimester abortion specially in developing countries [10]. In sub-Saharan Africa from overall unsafe abortion complications, $2 / 3$ of them are attributable to the second trimester period [11]. More than one-third of all women with abortion complications were seeking care after second trimester abortion and it was more common among women who lived in rural areas than among their urban counterparts in Ethiopia [12]. 
The Federal Ministry of Health in 2006 estimated that abortion-related deaths accounted for more than 30\% of maternal deaths in Ethiopia. Besides this, access to second trimester abortions is severely limited. Only $9-10 \%$ of all facilities have a provider who can perform this service [12].

As evidences showed, factors associated with second trimester termination of pregnancies were low use of modern contraceptive methods, restrictive abortion laws and policies, gender discrimination and lack of safe abortion services, stigma associated with abortion [11, 13-19], and relatively higher cost of late abortion care for nonmedical reasons though it was free of charge for medical reasons in countries like Mongolia [20]. Delay in making decision in first trimester due to either family/partner pressure or conflicting feeling about the pregnancy, lack of information about where to obtain an abortion, lack of providers, delay in testing and appointments, abortion associated stigma, the need to travel far from their home, and evidence of fetal anomalies or threats to health of mother were contributor to second trimester abortion $[6,21-23]$. A retrospective study conducted in Israel showed that age below 18 years, age above 40 years, or pregnancy outside of marriage were forces to have second trimester abortion [24]. A cross-sectional study in Amhara region reveals that $31.3 \%$ of women aged 15 to 49 were committing induced abortion due to fear of family and the community, and $14.1 \%$ were due to economic problem [9].

The Millennium Development Goal (MDG) to improve maternal health is unlikely to be achieved without addressing unsafe abortion and associated mortality and morbidity. Different study suggests that second trimester abortion is usually associated with higher rates of complications as compared to first trimester abortion $[1,25]$. Therefore, assessing the prevalence and associated factors of induced second trimester abortion is important for setting interventions to reduce the proportion of unsafe second trimester abortions and thereby saving the life of mothers from abortion-related morbidity and mortality.

\section{Methods}

2.1. Study Design, Area, and Period. Institution based crosssectional study was conducted in Amhara region referral hospitals. Based on the 2007 Census, the Amhara region has a total population of $17,221,976$ of whom $8,580,396$ were women. The region has 5 referral hospitals, 19 general/district hospitals, 220 health centers, and 2,941 health posts. The study was conducted from July 5, 2013, to January 5, 2014 (for 6 months).

All women who came for abortion service during the study period in Amhara region referral hospitals were the source population for study. Women excluded from study were those having gestational trophoblastic disease (partial mole) and those who cannot hear or are seriously ill with coma during data collection period.

2.2. Sampling. The sample size was calculated using single population proportion formula with $50 \%$ prevalence of second trimester abortion due to no previous study. Assuming a marginal error of $5 \%$ and $10 \%$ nonrespondent rate, the estimated sample size was 422 .

2.3. Sampling Procedures. The sample for each referral hospital was arranged based on their patient flow by reviewing the 6-month report of the previous year. After proportional allocation of the samples for each referral hospital, systematic sampling technique was used to select the study subjects and participants were interviewed based on their exit after they received all the necessary abortion care.

2.4. Data Collection Procedures and Statistical Analysis. Structured questionnaire which was developed by reviewing different literatures was used for the study. The questionnaire was prepared in English, translated to Amharic, and then translated back to English to check for consistency. Data was collected via exit interview. The data was collected by five BSc degree holder midwives, one in each referral hospital. Two supervisors who have BSc degree in midwifery were assigned for supervisory activities along with the principal investigator. Training was given to the data collectors and supervisors on the objective, relevance of the study, confidentiality of information, respondent's right, informed consent, and techniques of interview.

Before the actual data collection, pretest was conducted in Finote Selam Zonal Hospital for one month with 21 clients in May 2013 to ensure the validity of the survey tool and to standardize the questionnaire. The supervisor and the principal investigator made frequent checks on the data collection process to ensure the completeness and consistency of the gathered information and errors found during the process were also corrected.

Induced second trimester abortion was the dependent variable for study and the independent variables were sociodemographic factors (age, marital status, educational status, residence, monthly income, religion, ethnicity, husband's occupation, and educational status), reproductive characteristics (nature of menses, gravidity, parity, number of live births, current conditions of pregnancy, contraceptive history, and abortion history), logistical factors (taking time while finding money, transportation problem, referral problem, and not having information about where the service is given, distant from the institute), and medical factors (fetal deformity, maternal illness).

After data were collected, each questionnaire was given code and checked visually for completeness. The data were entered into Epi-info version 3.5.1 and transported to SPSS version 20 software packages for analysis. Data cleaning was performed using frequencies, sorting, listing to see missed values, and outliers and then correction was made by reviewing the original paper. Bivariate analysis was carried out first to observe the crude association between independent and outcome variables. The variables which have $P$ value $<0.2$ in bivariate analysis, not colinear, were entered into multiple logistic regressions to assess the net effect by controlling confounders. Finally, statistically significant variables which fit final regression model were identified using odds ratio with 95\% confidence interval and $P$ value $<0.05$. 


\section{Ethical Consideration}

Ethical clearance was obtained from Ethical Review Board (ERB) of University of Gondar Department of Midwifery. Letter of cooperation was obtained from the Amhara Regional Health Bureau and submitted to each referral hospital. Informed consent was also obtained from each client and introduced the objective of the study that it contributes to set interventions and strategies to improve services. Any client who was not willing to participate in the study had the right to refuse at any time of interviewing. Data were collected after full informed written consent is obtained and confidentiality of the information was maintained by excluding names as identification in the questionnaire and keeping their privacy during the interview by interviewing them alone.

\section{Results}

Out of 422 women who sought abortion services in Amhara region referral hospitals 416 women completed the interview administer questionnaire. Therefore, data analysis was made based on 416 cases that have been completing the interview. Response rate was $98.6 \%$.

4.1. Sociodemographic Characteristics. Among study participants more than one-third (141) (33.6\%) of them were in the age range of 20 and 24 years and the mean age was 24.4 $( \pm 6.32)$. Majority of the respondents were urban by residence (252) (60.6\%), Orthodox Christian (318) (76.4\%), married (193) (46.4\%), and housewives (154) (37\%), and not able to read and write (124) (29.8\%) and are having monthly income of $<26.3$ dollars (323) (77.6\%) and the median monthly income was 18.4 dollars. Among married women, their husbands' occupations are as follows: 88 (21.2\%) were private employee, 50 (12\%) government employee, 39 (9.4\%) farmer, and 16 (3.8\%) unemployed. Regarding husband's educational status of married women $56(13.5 \%)$ were able to read and write, $50(12 \%)$ were unable to read and write, $43(10.3 \%)$ had diploma and above, 29 (7\%) 9-12th, and 15 (3.6\%) 1-8th (Table 1).

4.2. Reproductive Characteristics. Two hundred sixty-eight $(64.4 \%)$ of respondents had regular menstrual cycle and the remaining one hundred forty-eight (35.6\%) had irregular menstrual cycle prior to the current abortion. Nearly sixty percent of the respondents were pregnant for the first time (248) (59.6\%), even though the pregnancy ended up with abortion. Majority of the respondents (333) (80\%) had been pregnant in the range between 1 and 3 times and the mode of gravidity was 1 . More than half of the cases (220) $(52.9 \%)$ were nullipara. Two hundred thirty-two $(55.8 \%)$ of the respondents did not have live birth (Table 2).

Only fifty-five (13.2\%) of women had abortion previously from which 38 (9.1\%) of them had termination of pregnancy at health institution and the remaining 17 (4.1\%) were spontaneously aborted at their home. From those who had abortion previously, $53(12.7 \%)$ of them had abortion 1 or 2 times and only $2(0.5 \%)$ had abortion more than 3 times.
TABLE 1: Sociodemographic characteristics of women who sought abortion service in Amhara region referral hospitals.

\begin{tabular}{|c|c|c|}
\hline Variables & $\begin{array}{l}\text { Frequency } \\
(n=416)\end{array}$ & Percent \\
\hline \multicolumn{3}{|l|}{ Age } \\
\hline $15-19$ & 101 & 24.3 \\
\hline $20-24$ & 141 & 33.9 \\
\hline $25-29$ & 78 & 18.8 \\
\hline $30-34$ & 53 & 12.7 \\
\hline$\geq 35$ & 43 & 10.3 \\
\hline \multicolumn{3}{|l|}{ Residence } \\
\hline Urban & 252 & 60.6 \\
\hline Rural & 164 & 39.4 \\
\hline \multicolumn{3}{|l|}{ Ethnicity } \\
\hline Amhara & 389 & 93.5 \\
\hline Oromo & 7 & 1.7 \\
\hline Tigre & 14 & 3.4 \\
\hline Others* & 6 & 1.4 \\
\hline \multicolumn{3}{|l|}{ Religion } \\
\hline Orthodox & 318 & 76.4 \\
\hline Muslim & 91 & 21.9 \\
\hline Protestant & 4 & 1.0 \\
\hline Catholic & 3 & 0.7 \\
\hline \multicolumn{3}{|l|}{ Marital status } \\
\hline Single & 173 & 41.6 \\
\hline Married & 193 & 46.4 \\
\hline Divorced & 44 & 10.6 \\
\hline Widowed & 6 & 1.4 \\
\hline \multicolumn{3}{|l|}{ Occupation } \\
\hline Housewife & 154 & 37.0 \\
\hline Student & 110 & 26.4 \\
\hline Merchant & 44 & 10.6 \\
\hline Government employee & 44 & 10.6 \\
\hline Farmer & 12 & 2.9 \\
\hline Daily laborer & 36 & 8.7 \\
\hline Others $^{* *}$ & 16 & 3.8 \\
\hline \multicolumn{3}{|l|}{ Monthly income } \\
\hline$<26.3$ dollars & 323 & 77.6 \\
\hline 26.3-52.6 dollars & 65 & 15.6 \\
\hline$>52.6$ dollars & 28 & 6.8 \\
\hline \multicolumn{3}{|l|}{ Educational status } \\
\hline Unable to read and write & 124 & 29.8 \\
\hline Able to read and write & 45 & 10.8 \\
\hline $1-8$ th & 98 & 23.6 \\
\hline $9-12$ th & 110 & 26.4 \\
\hline Diploma and above & 39 & 9.4 \\
\hline
\end{tabular}

Note: others $^{*}=$ Agew, Afar, others ${ }^{* *}=$ housemaid, jobless.

About 248 (59.6\%) of the respondents did not plan their pregnancies. However, terminated due to different nonmedical reasons such that $116(27.9 \%)$ of women did not want to lose their job/drop out of school as a result of the pregnancy, $88(21.2 \%)$ of them could not afford to cater a baby, $15(3.6 \%)$ had unsupportive friend/husband, and 22 (5.3\%) wanted to increase birth interval and only 7 (1.7\%) of terminations of pregnancy were because the woman is too young to raise a child. 
TABLE 2: Reproductive characteristics of women who sought abortion service in Amhara region referral hospitals $(n=416)$.

\begin{tabular}{lcc}
\hline Variables & Frequency & Percent \\
\hline Nature of menses & & \\
$\quad$ Regular & 268 & 64.4 \\
$\quad$ Irregular & 148 & 35.6 \\
Got pregnant before & & \\
$\quad$ It is my first time & 248 & 59.6 \\
$\quad$ Pregnant before & 168 & 40.4 \\
Gravidity & & \\
$1-3$ & 333 & 80.0 \\
$4-6$ & 60 & 14.4 \\
$\geq 7$ & 23 & 5.6 \\
Parity & & \\
0 & 220 & 52.9 \\
1 & 69 & 16.6 \\
2 & 52 & 12.5 \\
$\geq 3$ & 75 & 18.0 \\
Number of live births & & \\
0 & 232 & 55.7 \\
1 & 74 & 17.8 \\
2 & 49 & 11.8 \\
$\geq 3$ & 61 & 14.7 \\
\hline
\end{tabular}

On the other hand, one hundred sixty-eight (40.4\%) pregnancies were planned but terminated due to medical reasons such as $132(31.7 \%)$ due to the problem of the fetus and $25(6 \%)$ as a result of chronic illness of the mother and only $11(2.6 \%)$ of them were terminated because the continuation of pregnancy threatens the life of the women.

4.3. Prevalence of Induced Second Trimester Abortion. During the study period out of 416 women who sought abortion service in Amhara region referral hospitals 80 (19.2\%) of respondents had induced abortion and 60 (14.4\%) of respondents had spontaneous abortion in the second trimester period.

Seventy-six (18.2\%) of respondents had induced abortion during the early second trimester period between the gestational age of 13 and 20 weeks whereas the remaining four (1\%) were terminated between 21 and 28 weeks during late second trimester period. However, majority 276 (66.3\%) of respondents had abortion in the first trimester period (Figure 1).

4.4. Reasons for Delayed Seeking of Abortion Care. Nearly three-fourths of the respondents (299) (71.9\%) took $\leq 10$ days from confirming their pregnancy until they decided to have abortion, some of them (72) (17.3\%) took from 11 days up to 20 days, and only $45(10.8 \%)$ of the cases last 21 days and above.

Women who did not plan their pregnancy had mentioned different reasons why they did not seek early abortion service in the first trimester period. Out of 248 (59.6\%) unplanned pregnancies which were terminated due to different reasons,

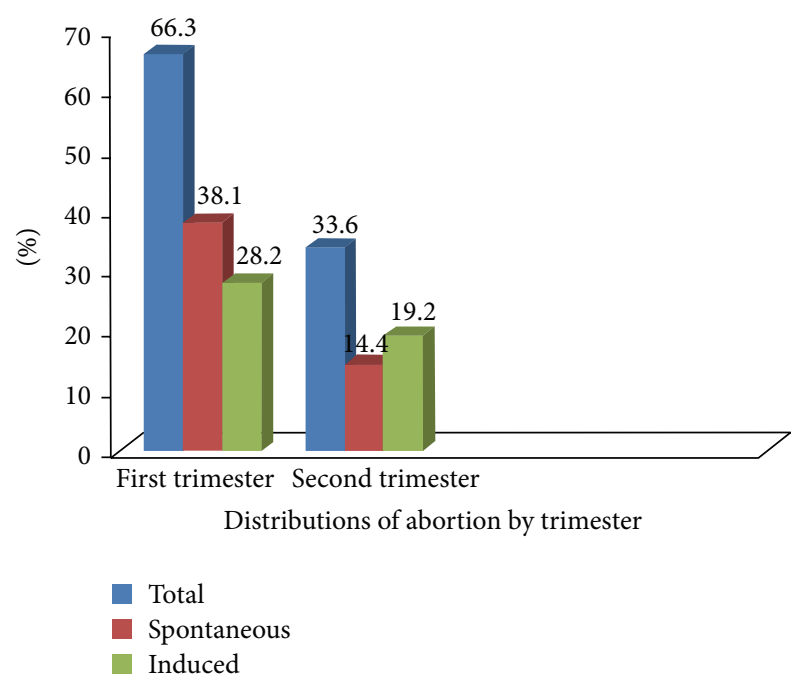

Figure 1: Distribution of abortion by trimester in Amhara region referral hospitals.

$186(44.7 \%)$ of the respondents were late because they did not recognize they were pregnant, $22(5.3 \%)$ took time while discussing about abortion with family/husbands, 17 (4.1\%) were confused either to terminate or to continue by peer pressure, $13(3.1 \%)$ took time because they were afraid to tell their family, and $10(2.4 \%)$ did not expect relationship with their husbands/freinds are changed.

4.5. Logistical Problems. Three hundred twenty-two (77.4\%) of the women who had abortion in the specified referral hospitals faced different problems related to logistics. About $178(42.8 \%)$ of the respondents waste their time while they found money for abortion expense, 96 (23.1\%) did not have information about where the abortion service is given, 23 (5.5\%) due transportation delay, $18(4.3 \%)$ due to referral delay from health center and only $7(1.7 \%)$ mentioned as they were distant from the institute.

4.6. Associated Factors of Induced Second Trimester Abortion. The residence of women, nature of menses, number of pregnancies, getting off from work, not being able to afford to cater a baby, not recognizing their pregnancy, and problem related to logistics were found to be associated with second trimester abortion in the bivariate analysis. Those variables were entered once into a backward stepwise multiple logistic regression model. Finally the model retains only those factors with significant associations at $P$ value $<0.05$ level. After adjustment, factors that increase risk of second trimester abortion were being more rural than urban by 1.86 times, having irregular menstrual cycle compared to regular by 1.76 times, not recognizing their pregnancy at early time compared to their counterparts by 2.05 times, and having logistics related problems (spent much time finding money for abortion expense) compared to not having problems by 2.37 times (Table 3). 
TABle 3: The bivariate and multiple logistic regression results on factors associated with induced second trimester abortion.

\begin{tabular}{|c|c|c|c|c|}
\hline \multirow{3}{*}{ Characteristics } & \multicolumn{2}{|c|}{ Induced second trimester abortion } & \multirow{2}{*}{\multicolumn{2}{|c|}{ With 95\% CI }} \\
\hline & No & Yes & & \\
\hline & Frequency (\%) & Frequency $(\%)$ & COR & AOR \\
\hline \multicolumn{5}{|l|}{ Residence } \\
\hline Urban & $215(85.3)$ & $37(14.7)$ & 1 & 1 \\
\hline Rural & $121(73.8)$ & $43(26.2)$ & $2.06(1.26-3.38)$ & $1.86(1.11-3.14)^{* *}$ \\
\hline \multicolumn{5}{|c|}{ Number of pregnancies } \\
\hline First $p_{x}$ & $191(77)$ & $57(23)$ & 1 & 1 \\
\hline 2nd $p_{x}$ and above & $145(86.3)$ & $23(13.7)$ & $0.53(0.31-0.90)$ & $0.79(0.45-10.43)$ \\
\hline \multicolumn{5}{|l|}{ Nature of menses } \\
\hline Regular & $231(86.2)$ & $37(13.8)$ & 1 & 1 \\
\hline Irregular & $105(70.9)$ & $43(29.1)$ & $2.56(1.56-4.20)$ & $1.76(1.03-2.98)^{*}$ \\
\hline \multicolumn{5}{|l|}{ Get off from work } \\
\hline No & $250(83.3)$ & $50(16.7)$ & 1 & 1 \\
\hline Yes & $86(74.1)$ & $30(25.9)$ & $1.74(1.04-2.92)$ & $1.19(0.62-2.29)$ \\
\hline \multicolumn{5}{|c|}{ Did not know she was pregnant } \\
\hline No & $200(87)$ & $30(13)$ & 1 & 1 \\
\hline Yes & $136(73.1)$ & $50(26.9)$ & $2.45(1.48-4.05)$ & $2.05(1.21-3.48)^{*}$ \\
\hline \multicolumn{5}{|c|}{ Cannot afford to cater baby } \\
\hline No & $272(82.9)$ & $56(17.1)$ & 1 & 1 \\
\hline Yes & $64(72.7)$ & $24(27.3)$ & $1.82(1.05-3.16)$ & $1.31(0.71-2.39)$ \\
\hline \multicolumn{5}{|l|}{ Logistical problem } \\
\hline No & $87(92.6)$ & $7(7.4)$ & 1 & 1 \\
\hline Yes & $249(77.3)$ & $73(22.7)$ & $3.64(1.62-8.22)$ & $2.37(1.02-5.53)^{*}$ \\
\hline
\end{tabular}

Note; $p_{x}=$ pregnancy, $\mathrm{COR}=$ crude odds ratio, and $\mathrm{AOR}=$ adjusted odds ratio $;{ }^{*} P<0.05$ and ${ }^{* *} P<0.001$.

\section{Discussion}

This study demonstrated that the overall prevalence of induced second trimester abortion was $19.2 \%$ which is in line with the prior study in South Africa that was $20 \%$ [26]. However, the finding of this study is greater than the global reported proportion $10-15 \%$ [10], study done in Nigeria 10\% [8] and New Delhi 2\% [27]. The possible explanation might be due to many women presenting to the government hospitals because private health institutions are not equipped to provide abortion care beyond 12 weeks of gestation except in rare occasions like private hospitals staffed by specialists (obstetrician/gynecologist). Moreover, different delaying factors may affect the women not to seek early abortion care in the first trimester period.

More than one-third of all women with abortion complications passed first trimester period and seeking care after second trimester abortion was more common among women who lived in the countryside as compared to urban residence in Ethiopia [12]. Likewise this study also revealed that being from rural residence is 1.86 times more likely to have abortion in the latter half of second trimester period as compared to urban women $(\mathrm{AOR}=1.86[95 \% \mathrm{CI}=1.11-3.14])$. Possibly women from the countryside may not have information about where the appropriate service is given and usually they are far from the institution.

A study done in New Delhi showed that factors affecting having second trimester abortion are difficulty in recognition of pregnancy and delay related to logistic problems [27].

The present study also highlighted that those women who did not recognize their pregnancy early were two times more likely to miss the opportunity to have abortion in the first trimester period than their counterparts $(\mathrm{AOR}=2.05$ [95\% CI $=1.21-3.48]$ ). The possible explanation might be irregular nature of women's menses results unsure of the missing period, thereby unable to pick early symptoms of pregnancy, and still time is needed for arrangements to have pregnancy test.

The strength of current study might be coverage of all referral hospitals within the region and relatively long duration of data collection over 6 months which could increase the representativeness of samples that possibly predict the outcome variable. However, this study might have limitations like any other cross-sectional study. It could not explain cause and effect relationship, and some respondents might not correctly remember their menstrual cycle prior to pregnancy.

In conclusion, the prevalence of induced second trimester abortion is high despite the availability of safe first trimester abortion services. Different delaying factors were preventing the women from getting early abortion services. Women who had faced problems related to logistics, women from rural residence, women who are unable to recognize their pregnancy early, and irregular nature of their menses were found to have an abortion in the second trimester period. Therefore Amhara Regional Health Bureau should further expand and strengthen safe second trimester abortion services below referral hospitals level to the level of general and district hospitals and make sure that accessible and affordable services are given. Organizations working on maternal health at different levels should give counseling for mothers to early recognize their pregnancy and to make decisions regarding either to continue it or not as early as possible. In addition, 
they should give logistical support for mothers who want to have abortion.

Further qualitative investigation is needed on underlying factors why women make late decision to terminate their pregnancy in the second trimester period.

\section{Conflict of Interests}

The authors declare that there is no conflict of interests regarding the publication of this paper.

\section{Acknowledgments}

The authors would like to thank Department of Midwifery, College of Medicine and Health Sciences, University of Gondar, for funding this research. Last but not least, they would like to thank all study participants and data collectors for their contribution in success of their work.

\section{References}

[1] S. Lalitkumar, M. Bygdeman, and K. Gemzell-Danielsson, "Mid-trimester induced abortion: a review," Human Reproduction Update, vol. 13, no. 1, pp. 37-52, 2007.

[2] Facts on Induced Abortion Worldwide, The Guttmacher Institute, New York, NY, USA, 2007.

[3] S. Singh, D. Wulf, R. Hussain, A. Bankole, and G. Sedgh, Abortion Worldwide: A Decade of Uneven Progress, Guttmacher Institute, 2009.

[4] G. Sedgh, S. Singh, I. H. Shah, E. Åhman, S. K. Henshaw, and A. Bankole, "Induced abortion: incidence and trends worldwide from 1995 to 2008," The Lancet, vol. 379, no. 9816, pp. 625-632, 2012.

[5] S. S. Dalvie, "Second trimester abortions in India," Reproductive Health Matters, vol. 16, no. 31, pp. 37-45, 2008.

[6] R. Ingham, E. Lee, S. J. Clements, and N. Stone, "Reasons for second trimester abortions in England and Wales," Reproductive Health Matters, vol. 16, no. 31, pp. 18-29, 2008.

[7] H. Gebreselassie, M. F. Gallo, A. Monyo, and B. R. Johnson, "The magnitude of abortion complications in Kenya," BJOG, vol. 112, no. 9, pp. 1229-1235, 2005.

[8] V. O. Awusi and V. Okeleke, "Post induced abortion morbidity and mortality in Oleh, Nigeria," Benin Journal of Postgraduate Medicine, vol. 12, no. 1, 2011.

[9] E. Senbeto, G. D. Alene, N. Abesno, and H. Yeneneh, "Prevalence and associated risk factoprs of induced abortion in Northwet Ethiopia," Ethiopian Journal of Health Development, vol. 19, no. 1, pp. 37-44, 2005.

[10] I. Shah and E. Ahman, "Unsafe abortion: global and regional incidence, trends, consequences, and challenges," Journal of Obstetrics and Gynaecology Canada, vol. 31, no. 12, pp. 1149-1158, 2009.

[11] S. Singh, "Hospital admissions resulting from unsafe abortion: estimates from 13 developing countries," The Lancet, vol. 368, no. 9550, pp. 1887-1892, 2006.

[12] Guttmacher Institute and Ipas, Facts on Unintended Pregnancy and Abortion in Ethiopia, Guttmacher Institute and Ipas, 2010.

[13] K. L. Turner, A. G. Hyman, and M. C. Gabriel, "Clarifying values and transforming attitudes to improve access to second trimester abortion," Reproductive Health Matters, vol. 16, no. 31, pp. 108-116, 2008.

[14] N. Prata, S. Bell, M. Holston, C. Gerdts, and Y. Melkamu, "Factors associated with choice of post-abortion contraception in Addis Ababa, Ethiopia," African Journal of Reproductive Health, vol. 15, no. 3, pp. 51-57, 2011.

[15] J. Healy, K. Otsea, and J. Benson, "Counting abortions so that abortion counts: indicators for monitoring the availability and use of abortion care services," International Journal of Gynecology and Obstetrics, vol. 95, no. 2, pp. 209-220, 2006.

[16] A. Ceylan, M. Ertem, G. Saka, and N. Akdeniz, "Post abortion family planning counseling as a tool to increase contraception use," BMC Public Health, vol. 9, article 20, 2009.

[17] J. Harries, P. Orner, M. Gabriel, and E. Mitchell, "Delays in seeking an abortion until the second trimester: a qualitative study in South Africa," Reproductive Health, vol. 4, article 7, 2007.

[18] "International conference on second trimester abortion: recommendations, 29-31 March 2007," vol. 16, no. 31, pp. 205-206, 2008.

[19] B. K. Suvedi, A. Pradhan, S. Barnett et al., Nepal Maternal Mortality and Morbidity Study 2008/2009: Summary of Preliminary Findings, Family Health Division, Department of Health Services, Ministry of Health, Government of Nepal, Kathmandu, Nepal, 2009.

[20] B. Tsogt, K. Seded, and B. R. Johnson, "Applying the WHO strategic approach to strengthening first and second trimester abortion services in mongolia," Reproductive Health Matters, vol. 16, no. 31, supplement, pp. 127-134, 2008.

[21] R. Boland, "Second trimester abortion: still a neglected topic," ICMA NEWS Newsletter, no. 5, 2011.

[22] M. F. Gallo and N. C. Nghia, "Real life is different: a qualitative study of why women delay abortion until the second trimester in Vietnam," Social Science \& Medicine, vol. 64, no. 9, pp. 18121822, 2007.

[23] E. A. Drey, D. G. Foster, R. A. Jackson, S. J. Lee, L. H. Cardenas, and P. D. Darney, "Risk factors associated with presenting for abortion in the second trimester," Obstetrics \& Gynecology, vol. 107, no. 1, pp. 128-135, 2006.

[24] D. Vitner, M. Deutsch, Y. Paz et al., "Association between gestational age and induction-to-abortion interval in midtrimester pregnancy termination using misoprostol," European Journal of Obstetrics Gynecology \& Reproductive Biology, vol. 156, no. 2, pp. 140-143, 2011.

[25] E. Janiak, I. Kawachi, A. Goldberg, and B. Gottlieb, "Abortion barriers and perceptions of gestational age among women seeking abortion care in the latter half of the second trimester," Contraception, vol. 89, no. 4, pp. 322-327, 2014.

[26] South African Department of Health, Termination of Pregnancy Update: Cumulative Statistics Through 2004, Department of Health, Pretoria, South Africa, 2005.

[27] P. Aggarwal, P. Agarwal, V. Zutshi, and S. Batra, "Do women presenting for first and second-trimester abortion differ sociodemographically?" Annals of Medical and Health Sciences Research, vol. 3, no. 2, pp. 187-190, 2013. 


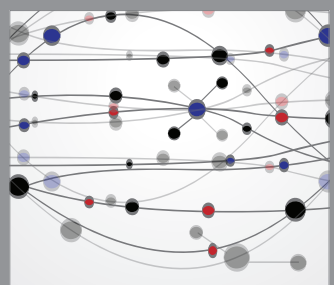

The Scientific World Journal
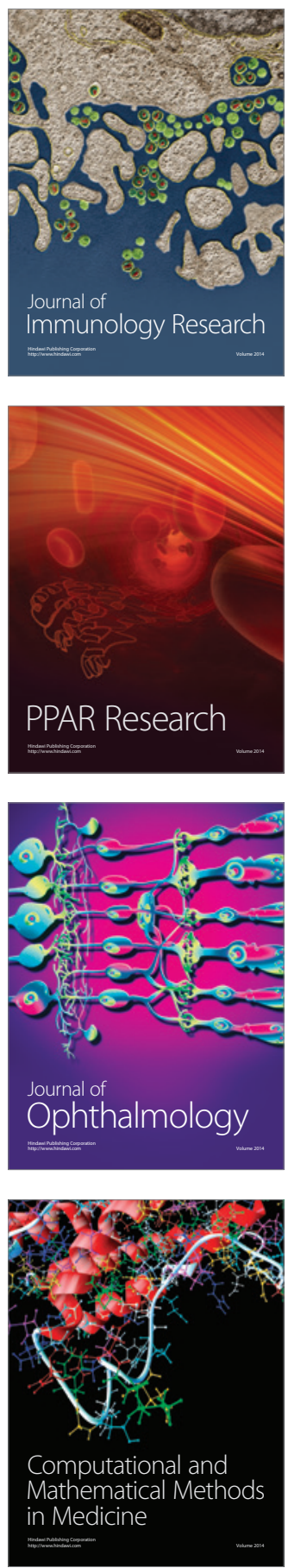

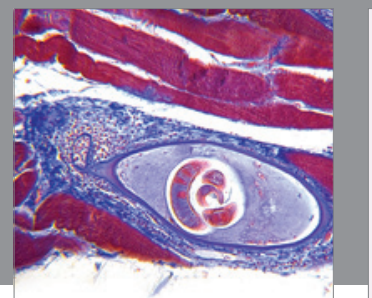

Gastroenterology

Research and Practice
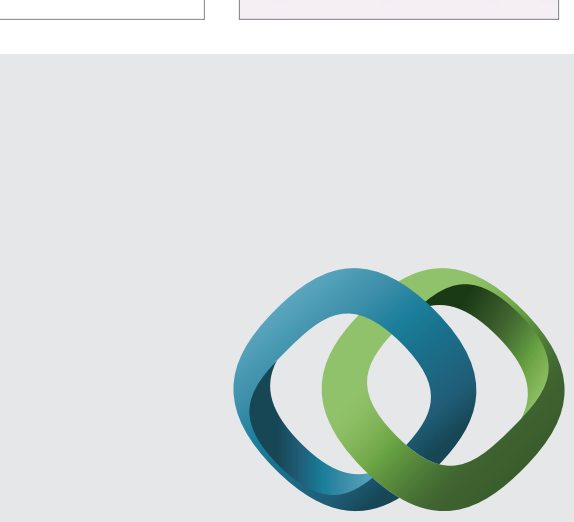

\section{Hindawi}

Submit your manuscripts at

http://www.hindawi.com
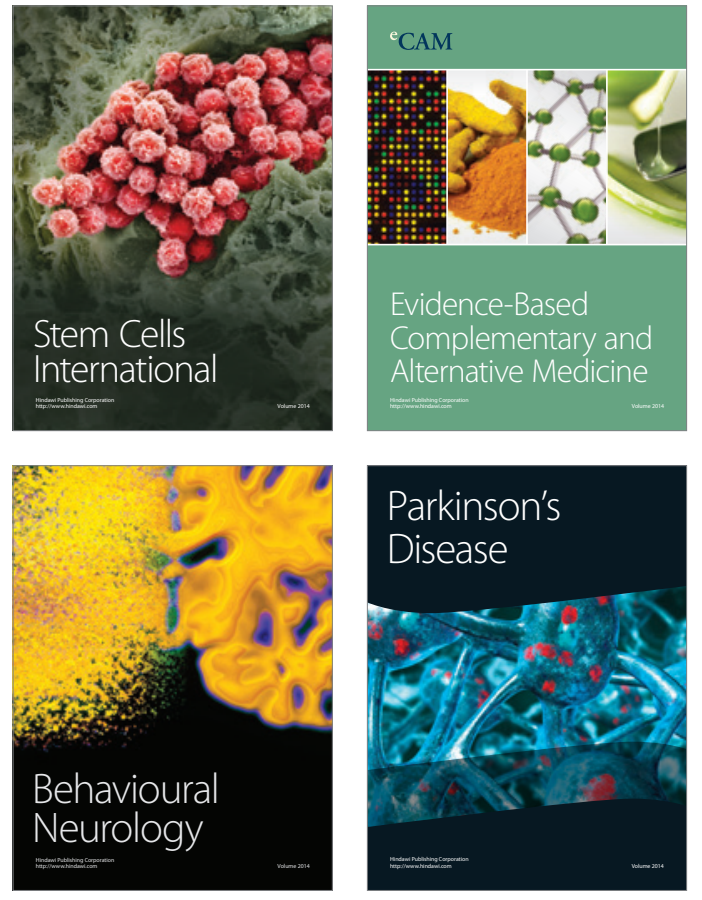
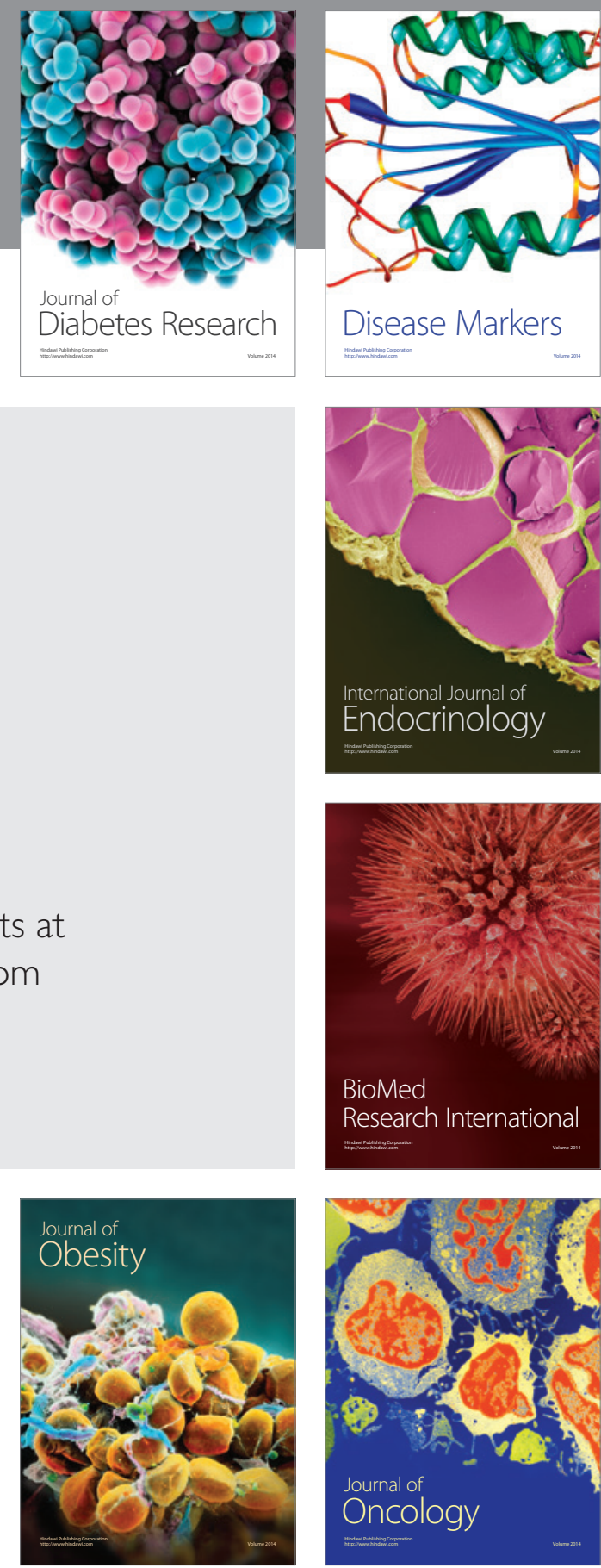

Disease Markers
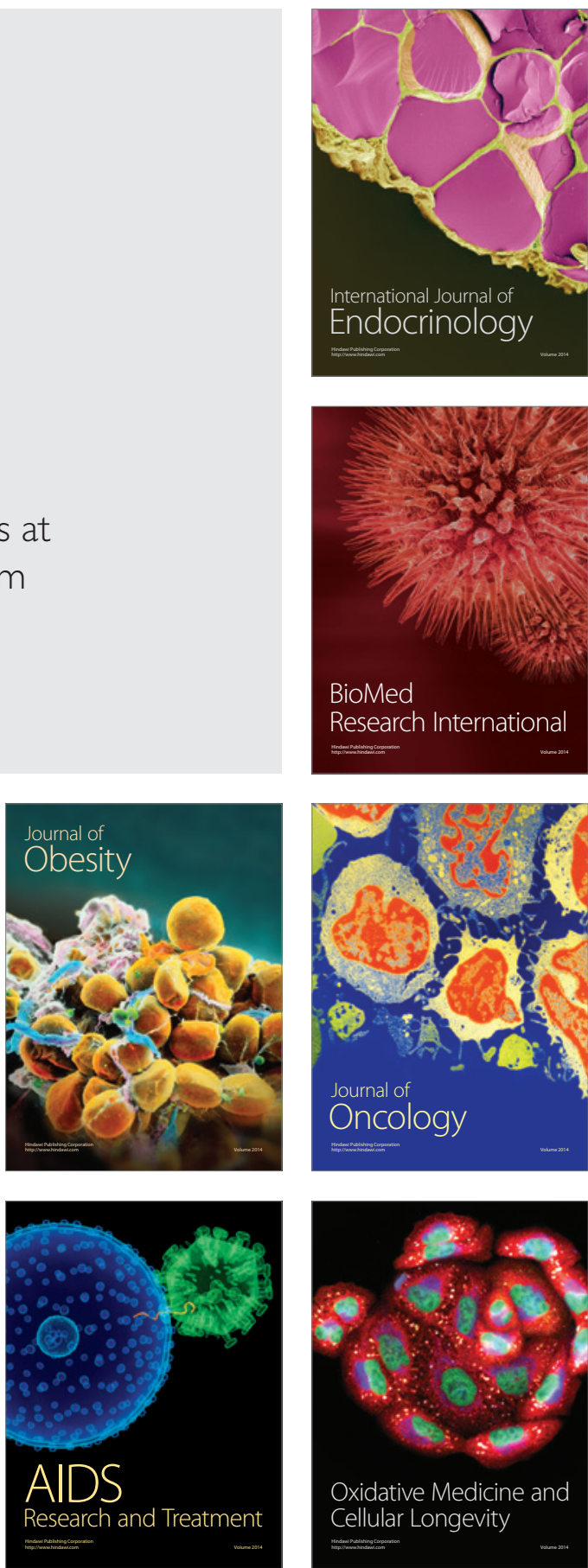